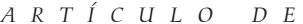

$\begin{array}{llllllllll}R & E & F & L & E & X & I & O & N\end{array}$

\title{
LOS LENGUAJES DE LA MÚSICA UN EJE TRANSVERSAL DEL CURRÍCULUM
}

MUSIC LANGUAGES A TRANSVERSAL CORE OF THE CURRICULUM

Por: Manuel Pérez Herrera*

Recibido: 8 de octubre de 2017 - Aprobado: 30 de mayo de 2018

* Profesor tiempo completo - Titular - Investigador Universidad de Atlántico. Director de grupo de investigación Música - Cultura y Tradición, reconocido por Colciencias. Doctor en Ciencias de la Educación, RUDECOLOMcacion, RUDECOLOMBIA, Universidad de Caldas, Manizales. Licenciado en Educación Musical; Especialista en Evaluación Educativa magíster en Educación y Cognición: Becario en doble titulación doctoral Universidad de toral, Universidad de Granada España

\section{RESUMEN}

El curriculum que presentamos se devela como el "eslabón" entre la investigación formativa y equilibrada de "códigos universales y códigos del contexto", es decir, las concepciones de los saberes "elaborados" como los no elaborados, "restringidos". Acápite científico curricular, que permite ampliar el marco de posibilidades de acceder a nuevos conocimientos científicos - socio culturales, con identidad, y en procura de mantener la comunicación dialógica constante entre los lenguajes musicales, la investigación y la producción musical en contextos. Propuesta curricular que se concibe a través de la puesta en marcha de una didáctica constructivista alternativa que integre prácticas y saberes en un currículo comprensivo, atendiendo así propósitos como los de encontrar equilibrio en los significados de la música desde una práctica pedagógica mediadora del pensar - sentir y hacer, de los sujetos cognoscentes, quienes comprenden por qué la música se constituye en lenguaje que transversaliza lo humano y lo científico.

Palabras clave: Lenguajes musicales, Curriculum transversal, Investigación formativa, Transformación, Tipos de desarrollo.

\begin{abstract}
The curriculum that we present is revealed as the "link" between the formative and balanced research of "universal codes and context codes", that is, the conceptions of "elaborated" knowledge as those that are not elaborated, "restricted". Scientific curricular section, which allows to expand the framework of possibilities of accessing new scientific - socio - cultural knowledge, with identity, and in order to maintain the constant dialogical communication between musical languages, research and musical production in contexts. Curricular proposal that is conceived through the implementation of an alternative constructivist didactics that integrates practices and knowledge in a comprehensive curriculum, thus serving purposes such as finding balance in the meanings of music from a mediating pedagogical practice of thinking - feeling and doing, of the knowing subjects, who understand why music is constituted in a language that transverses the human and the scientific.
\end{abstract}

Keywords: Musical Languages, Transversal Curriculum, Formative Research, Transformation, Types of Development. 
La didáctica constructivista alternativa integra prácticas y saberes en un currículo que busca equilibrio entre la cultura universal y la cultura del contexto (Pérez, 2010)1.

\section{Introducción}

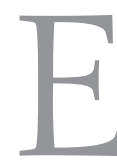

l presente artículo es producto de los procesos de investigación formativa realizados con estudiantes de diversos programas en la Universidad del Atlántico, y, el mismo buscó la dinamización de procesos académicos-investigativos, en los cuales convergen con identidad la formación integral de los sujetos y la práctica pedagógica investigativa, concebida esta última, como un todo integrador de los lenguajes de la música ejercitados como ejes transversales del currículum. Esta nueva propuesta curricular es abordada, planeada, ejecutada y evaluada, teniendo en cuenta los principios filosóficos y científicos de la educación social, complejo académico del cual se genera la didáctica constructivista alternativa de la música y del currículum, desde la cual se desarrollaron acciones educativas que fundamentan el conocimiento teórico-práctico y los actos de enseñarevaluar y aprender en los programas de Educación generalizada en diversos contextos de la Universidad. En consecuencia, quienes se comprometieron con esta nueva perspectiva científica de la música como eje transversal del currículum encontraron mayor significado a sus prácticas pedagógicas investigativas-formativas.

Los objetivos (general-específicos) que guiaron el estudio son:

- Integrar los lenguajes de la música como ejes transversales del currículum, fundamentados en una didáctica constructivista alternativa de la música y en una organización de contenidos y prácticas que permitan dinamizarlos como elementos que impactan significativamente los tipos de desarrollo en contexto.

- Diagnosticar el estado del arte de la integración del conocimiento y la práctica educativa musical en contexto real, con el propósito de conocer intereses, necesidades y valores de la comunidad educativa y presentar acciones en procura del desarrollo coherente de un currículum que transversaliza los lenguajes de la música.

- Indagar sobre las percepciones de los actores en la vida escolar en torno a la existencia, integración y proyección de la música como 
eje integrador del currículum en programas académicos en general, como referentes válidos y confiables para los fines de la investigación.

- Generar nuevos espacios educativos para la construcción de prácticas y saberes integradores, partiendo de principios democráticos, expresivos, libertarios y de disfrute de una educación musical humanizadora del ser y su contexto social.

La puesta en práctica de la didáctica constructivista alternativa, condujo a la comunidad participante hacia la construcción de nuevos conocimientos productos de las acciones conscientes de los sujetos del saber, quienes permanentemente lograron el contacto directo con objetos de conocimiento de los lenguajes de la música. De esta manera se logra la integración de nuevos participantes en este proceso activo transformista y donde los sujetos como seres culturales, comprendieron con mayor sentido el rol de la música en su formación integral, y no obstante lograron romper la resistencia reduccionista del pensamiento estacionario del "medioevo", donde la música fue vista como objeto utilitario-instrumental de prácticas empíricas, en tal sentido, en el hoy los sujetos del saber la ejercitaron e hicieron nuevas construcciones y reelaboraciones como embates transformadores y productivos de una cultura musical educativa para la vida.

En consecuencia, la didáctica constructivista alternativa en atención al currículum, fue concebida como un paradigma social - cultural - educativo, el cual es "poseedor de un conjunto de rasgos característicos entre los cuales se destaca la presencia de un relativismo curricular-musical y cultural subyacente en la realidad social" (Álvarez, 2001, p. 15). Además que fueron propósitos de la implementación propuesta curricular, la construcción de nuevos escenarios pedagógicos que consolidaron la socialización de los actores implicados en el proceso, quienes interactuaron con la comunidad académica, fundamentados en el enfoque epistemológico didáctico constructivista, articulados con la crítica social y el pensamiento progresivo de Escuela Nueva, desde donde se condujo la formación integral del estudiante, validando su ser, su saber y su hacer desde su contexto vital (Pérez, 2014).

De los anteriores supuestos científicos, filosóficos y educativos, se infiere que el nuevo conocimiento generado se fundamenta en factor dinamizador de desarrollo cultural, exigencia en el hoy del marco de la competitividad y del mundo globalizado. No obstante que "el conocimiento, la sociedad y la 
cultura es el valor agregado de la producción" (Magendzo, 1986, p. 34). Por su parte, Quintana (1976, p.34), considera "la importancia de lograr hacer redes de comunicación y de construcción de teorías y prácticas sociales a partir del arte", lo que para quienes están comprometidos con la educación artística musical integradora, este sistema curricular transversal se moldee como andamiaje genérico de concreción dinámica de procesos de intervención, acompañamiento y transformación conscientes de activos culturales que se manifiestan en los contextos como factores constitutivos de identidad y desarrollo social - ciudadano.

"[...] En este tipo de didáctica alternativa, "no se puede separar individuo y sociedad como si fueran objetos distintos, las estructuras sociales sólo existen a través de su continua producción por parte de los individuos quienes desarrollan prácticas y le dan significado a lo que construyen" (Ibáñez, 1999). "[...] es por ello, que la educación social se constituye en un conjunto de prácticas diversas, por ende, es un espacio en el cual se atiende la producción de efectos de inclusión cultural, social y económica, al dotar a los sujetos de los recursos pertinentes para resolver los desafíos del momento histórico." (Núñez, 1990, p. 26).

Desde punto de vista de la educación social, la didáctica constructivista alternativa de la música, igualmente "fundamenta el sentido de la filosofía de aquel arte que se interesa por analizar la relación adentro (saber artístico musical - escolar), afuera (saber artístico socialmente circulante) en función de la actividad artística, con el fin de detectar las rupturas o discontinuidades entre ambas formas del saber artístico" (Lobo, 1999, p. 36).

\section{Diseño curricular de los lenguajes de la música como un eje trans- versal del currículum.}

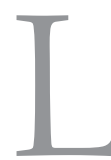

a orientación de los procesos de formación logró la comprensión interpretativa de los lenguajes de las música tales como: la representación de signos y símbolos musicales, ambientes sonoros - música de tradición - oralidad - coordinación rítmico - motriz - vocal - tonal - audioperceptivosensoriomotor - gesticular - aptitudinal - sonoridad - poético - gramatical - pulso - acento - metro - métrica - rima - estética - danza, entre otros. Por ello, la misión-visión de la propuesta curricular, apunto de principio a fin a la formación de estudiantes de una educación generalizada, pertenecientes a diversos programas académicos de la Universidad, cuya ruta de aprendizaje 
Manuel Pérez Herrera

fueron los lenguajes de la música citados, y orientados de forma transversal, teniendo en cuenta el reconocimiento histórico, cultural, estético, científico, social y tecnológico, generadores estos de todo tipo de desarrollo logrado en los contextos.

Por todo lo anterior, el complejo de integración del currículum transversal y la didáctica constructivista alternativa de la música, visiona a un profesional constructor de conocimiento holístico y visionario de diversos tipos de desarrollo humano-cultural en la formación de formadores. En ese sentido, las estrategias metodológicas utilizadas fueron dirigidas a la activación comprensiva de la didáctica constructivista alternativa de la música que como constructo social jalonó lenguajes emocional - volitivo - actitudinal conceptual - estético, corporal - rítmico - audioperceptivo - motriz - vocal - tonal - expresivo - la danza y demás formas simbólicas representativas de esta disciplina integradora.

Por su parte Fernández, y otro (1992, p. 4), consideran que la transversalidad puede suponer un elemento significativo e interesante, una propuesta sugestiva por dos razones:

1. Por considerar la transversalidad como un concepto innovador, por dotar al currículum de una considerable riqueza y variedad de contenidos que pueden ser organizados en infinidad de formas, de manera que den respuesta a las necesidades de los alumnos.

2. Porque las necesidades emanadas a este respecto entre el profesorado son un síntoma importante de la resonancia que la propuesta tiene.

\section{Enfoque conceptual.}

\ l currículum visionado como tentativa de cambio y/o eslabón investigativo en un proceso interactivo cultural (Stenhouse, 1997), tal posición conceptual contribuye a fundamentar la didáctica constructivista alternativa que se presenta, en el sentido que acoge al sujeto de valores y de derecho como constructor de su proyecto de vida y de formación académica en contexto real. Magendzo (2003, p. 14), supone que "se es consciente que la cultura general, se debe sustentar en el ámbito de una didáctica social que tenga sus raíces en los discursos culturales y en las tradiciones". No obstante, que la música es un universo 
de múltiples lenguajes relativos que se manifiestan inconscientemente en la conciencia espiritual- emocional - perceptiva - motriz - auditiva - social - estética, etc., y, por lo tanto, no se pueden establecer los efectos que producen en los seres humanos como formas y estructuras absolutas.

En tal sentido, le corresponde a los interesados en desentrañar y resignificar los saberes y prácticas musicales, empezando por dar cuenta de sus orígenes e historias, reescribiendo comprensivamente sus marcos contextuales, culturales y sociales. Esta mediación investigativa se puede considerar como un dispositivo de "englobe social" (García Canclini, 1995). Por su parte, la "Escuela Nueva", visiona la historia social de la educación y el currículum, como una acción social que se inscribe en el proceso de masificación de la educación, en donde adquiere fuerza la idea de que la educación desempeña un papel importante en el cambio social. Al mismo tiempo, de intervención comprensiva para dar cuenta de cómo ha evolucionado en diversos periodos, y, "[...], cómo han sido los cambios generadores de nuevas estructuras en las comunidades" (Habermas, 1948, p. 19). Por eso, es tarea inaplazable de la educación en el siglo XXI, poner a "dialogar" en igualdad de condiciones la cultura del contexto con la cultura universal, hasta encontrar el equilibrio de actuación, estructuración, y valoración conjunta del saber popular y científico, camino al reconocimiento de la humanidad plena (Freire, 1974).

En la investigación, las teorías epistemológicas constructivistas-cognitivas de Jean Piaget (1954), y Lev Vygotsky (1979), fueron articuladas con los supuestos científicos que emergen de estudios sociales sobre el desarrollo humano y otros factores significativos que parten de la psicología y que de manera integral se centran en las etapas evolutivas del desarrollo del ser, las cuales se orientan desde la infancia hacia la madurez, en sus diferentes ámbitos y niveles de formación (Ley General de Educación, Ley 115 1984, p.12). Tales posiciones epistemológicas psicológicas, cognoscitivas, constructivistas, humanísticas, entre otras formaron un juego interdisciplinario en el desarrollo humano y los conocimientos que lograron reproducir y construir conscientemente los educandos (as).

En ese discurrir evolutivo de los educandos y los objetos de conocimientos, se establecieron acercamientos y rutas de aprendizaje que trasciende ámbitos filosóficos, culturales, biopsicosociales y genético. Por ello encontramos que la pedagogía moderna del siglo XXI, contradice la manera como se visionó al ser humano en el pasado y las formas como se fue dando "deliberadamente 
el conocimiento como hecho psicológico en tanto proceso social, genético, psicológico, lingüístico, cultural, ético, artístico, etc., y como hecho epistemológico en tanto conocimiento válido, histórico, experimental, formal" (Lobo, 1999, p.13).

En el proceso investigativo, la comunidad hizo uso de la libre participación en los procesos de formación y de expresión artística, en la construcción de valores personales, interpersonales y los propios del contexto, la identidad cultural y el derecho a una práctica pedagógica eficaz, creativa y recreativa como bienes y derechos que otorga la ley. Postulados sociológicos visibles en una educación musical constituida en eje dinamizador de la conciencia espiritual-creativa y lúdica del hombre, como el único espacio natural que lo invita a sociabilizarse de distintas maneras; es decir, la música como factor social está llamada a devolverle la alegría a los contextos naturales y al aula escolar; y para los educandos se erige como eje estimulante de su desarrollo integral.

Por todo lo expuesto, es lógico comprender la implicación que tiene esta disciplina en el desarrollo humano integral, igualmente, en la manera como se erige en mediación fundamental de la formación de un profesional competente y competitivo, capaz de enfrentarse conscientemente a las exigencias profesionales y valorativas del mundo moderno de la complejidad, la competitividad y la globalización.

\section{Diseño de investigación}

Tra investigación de factores musicales y las implicaciones sociales

y la consciencia multidimensional de los sujetos, desde la didáctica $ـ$ constructivista alternativa logró la proyección de los participantes, con los cuales se realizaron diagnósticos de necesidades y valores, para luego revalorar sus propios problemas de aprendizaje y el entorno, al tiempo que fue capacitado para que sea constructor de nuevas prácticas y teorías científicas. De esa manera, la integración de prácticas y saberes musicales desde un currículum transversal posibilitó la fundamentación de la formación de la capacidad creativa de estudiantes transformadores de discursos musicales científicos, sociales y culturales.

En consecuencia, desde la nueva perspectiva didáctica constructivista alternativa de la música y del currículum, se tuvo en cuenta que el Área de Educación Artística-Musical, dentro de sus planteamientos devela la manera 
eficiente, competente y eficaz de cómo comprender, intervenir, diagnosticar, transformar y ejecutar nuevas perspectivas teóricas-discursivas y prácticas de la música que dan cuenta del ser, el hacer y el saber de los sujetos, en consonancia con su pensar, sentir y actuar.

En tal sentido, la intencionalidad académica didáctica formativa, se orientó por una filosofía social-dialógica integradora del ser, el contexto y el conocimiento, logrando establecer una práctica educativa de calidad. De esta forma, se justifica el por qué y para qué de un sistema educativo que acoge a los seres humanos de manera integrativa, todo lo anterior teniendo en cuenta los principios normativos que establece la Constitución Política de Colombia (1991), acordes con los marcos normativos de la educación colombiana y con organismos internacionales que le apuestan al desarrollo democrático y participativo de una educación coherente con su estructura orgánica: marcos teleológicos, institucionales, modelos educativos, enfoques teóricos, sistemas didácticos, diseños curriculares, prácticas investigativas, desarrollos formativos, psicológicos, valorativos, prácticas educativas, etc., que hagan posible la integración de conocimientos y de desarrollo humano, mediados por un clima de concertación, convergencia social, de participación y colaboración, entre la institución, los docentes, los (las) estudiantes y la comunidad objeto de beneficio de la educación artística-musical en contextos geográfico divergentes.

En este tratado teorético musical-curricular, la relación educación-sociedad, exige que el currículo contribuya eficazmente a la formación integralciudadana y a la conciencia crítica (Sacristán, 1980, p. 33). Es decir, de una conciencia que con vigor y responsabilidad, pueda plantear y resolver verdaderos problemas y buscar distintas formas de solución y transformación a los mismos. No obstante, el diseño curricular de la música que se presenta, en todos sus ámbitos hace énfasis en una formación educativa e investigativa de la música como eje transversal del currículo orientado desde la institución educativa y proyectada integralmente hacia la transformación de los contextos socio-culturales.

La consolidación del desarrollo humano, en la propuesta curricular, se dio en la integración de procesos cognitivos, afectivos, conceptuales y actitudinales. En la implementación del plan curricular se tuvo en cuenta dinamizar talleres y seminarios integrativos del conocimiento, los cuales serán evaluado periódicamente significando logros e indicadores propuestos para la 
Manuel Pérez Herrera

conquista de saberes múltiples transdisciplinares, en los cuales las destrezas, las habilidades y demás dimensiones y capacidades físicas, psicológicas, cognitivas y sociales, forman el tejido conductor de la práctica pedagógica de calidad, en espacios lúdicos, creativos y recreativos del conocimiento vivencial, actitudinal, experiencial, experimental y demás niveles de desarrollo.

\section{Procesos metodológicos}

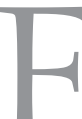

n el estudio la planeación de las actividades de la disciplina musical en el currículum transversal, (práctica pedagógica investigativa), se organiza en cuatro niveles y/o unidades:

A: Seminarios-talleres. Este primer nivel corresponde a la educación infantil (preescolar), la orientación en esta primera fase se fundamentó en una etapa experimental (laboratorio experiencial) y la reflexión se centró en el trabajo lúdico-recreativo con los infantes, haciendo mucho énfasis en la utilización de recursos artísticos que surgen del contexto, los cuales estimulan las actividades que desarrollan los (as) menores; los estudiantes pudieron apreciar gran variedad de sensaciones y sentimientos (alegría - tristeza - diversiones - emociones). Para Maravillas Díaz (2004, p. 13): “Es importante señalar que, el trabajo en el preescolar, en la básica primaria y secundaria, los temas transversales se deben fundamentar en aspectos que tengan que ver con la cultura del contexto, las artes, las tradiciones, el folclor, costumbres, geografía, historias, personajes, etc.", además se agregaron otras temáticas que resulten de interés a los (as) educandos y que, a su vez, forjen sus capacidades cognoscitivas. Consideramos que en este nivel de formación la práctica pedagógica debería estar encaminada a desarrollar las dimensiones sensorio-motoras, psico-motriz, auditivas, audio-perceptiva, conciencia estética y, por ende, el desarrollo cognoscitivo. (Pérez, 2010, p.70).

En este tipo de propuesta de integración curricular, humana y de estructuras de pensamiento, es indispensable dirigir la actividad formativa hacia el afianzamiento del desarrollo de la experiencia-estimulación sensorio-motora (Piaget, 1954, p. 36) y la Zona de Desarrollo Próximo (Vygotsky, 1979: 45). Aspectos estos que se constituyen en mediadores del conocimiento de lo humano, de lo cultural y de lo musical. Por eso, consideramos prioritario afianzar el conocimiento previo de los individuos $\mathrm{y}$, a partir de allí, dirigir los procesos y actividades educativas a favorecer el desarrollo del lenguaje, de la expresión, del manejo del cuerpo, del movimiento y del ritmo musical coordinados, utilizando canciones que contengan grandes contenidos 
socioculturales y sentido artístico, con características críticas, divertidas y emocionantes, los cuales ellos (as) puedan asimilar, representar y dramatizar los aprendizajes de la música logrados desde los procesos de la práctica pedagógica integrándolos con otros saberes. (Lineamientos curriculares. 2000, P. 19).

Las acciones artístico-musicales se desarrollan pensando en este nivel de formación, variando los contenidos de las temáticas procesalmente, según intereses, intensidad y como exigencia académica, por lo que la primera acción posibilitó que los educandos conozcan, comprendan, interroguen y entren en contacto con el lenguaje musical, utilizando primero el cuerpo humano como instrumento natural y recurso indispensable para una buena formación musical, vocal expresiva, corporal, emocional, actitudinal, psicomotora, socioafectiva, audio-perceptiva, y otras. En el proceso, igualmente se interrogó ¿cómo iniciar la clase?: si es propicio primero utilizar el canto, la expresión corporal, con la ayuda de escenografías, actividades de narración oral y actuación, para estimular la experiencia sensorio-motora. Aquí la Zona de Desarrollo Próximo ejerce el rol de reconstrucción conceptual y el logro de nuevas representaciones que harán los sujetos entre sí y con los objetos de conocimiento musical. De esta forma, logramos la socialización e integración de los (as) educandos, quienes podrán reproducir lo aprendido desde el manejo de la voz y la utilización correcta del cuerpo, como de algunos instrumentos musicales introducidos previamente a la práctica pedagógica y, por ende, la integración con los demás lenguajes tanto artísticos, como de otras áreas del conocimiento. (Pérez, 2012, P.11).

B: En el segundo nivel: básica primaria, se retoma la acción de formación inicial. La acción fue encaminada a la identificación de la música en el desarrollo de la inteligencia y del pensamiento crítico y se buscaba estructurar los elementos musicales y su asociación corporal, visual, estética, social, histórica, cultural, con imágenes reales. En este ámbito educativo, la estrategia didáctica constructivista alternativa fue orientada al desarrollo de la inteligencia a través del conocimiento de objetos musicales, tales como símbolos, figuras, códigos, signos e instrumentos, de tal manera que los (as) estudiantes pudieran manipularlos, jugar con ellos, interactuar con la acción rítmico-melódica, el acento, el pulso, manifestando corporalmente lo que sienten, perciben y lo que imaginan, y además, asimilar lo aprendido a otro plano representativo de la organización de conocimiento interdisciplinario. (Pérez, 2012, P.151). 
Los y las educandos participantes de la propuesta, entran en contacto directo en la práctica del canto y la percusión rítmica, utilizando primero su propio cuerpo y luego con instrumentos de percusión conocida y fácil de manipular, ejecución instrumental básica para la fijación de motivos musicales cantados, percutidos y la construcción de discursos vocales y escriturales.

C: En el tercer nivel: básica secundaria, se retoma la acción de los niveles anteriores y se retro-alimentan desde la práctica pedagógica, abriendo espacios para el desarrollo de esta perspectiva didáctica constructiva investigativa implementada para reorientar el conocimiento teórico - práctico de la música, comprendiendo que el niño (a) y los (as) y jóvenes en este nivel educativo, ya han logrado asimilar, acomodar, adaptar, organizar y reconstruir estructuras nuevas de pensamiento (Piaget, 1954, P. 36). Todo lo anterior, es producto de la evolución cronológica, lógica, psicológica y cognitiva de los alumnos. Es decir, no solo se buscó la ejercitación sensorio-motora, sino también que todos (as) desarrollen pensamiento lógico meta-representativo, y transferir lo aprendido, desde su puesta en común y desde la misma elaboración de contenidos y de instrumentos musicales con materiales reciclables, y ejercitar actividades lúdicas creativas como músico-drama, escenificación de saberes multidisciplinares, dramatizaciones con leyendas, cuentos, mitos, canciones, narraciones y otras, "(planos: interpsicológico-intrapsicológico)". En este entorno del conocimiento, la capacidad de comprensión, entendimiento y análisis, afianzan lo estadios de abstracción superior (internalización). (Vygotsky, 1979, P. 66).

D: Nivel cuarto, la práctica pedagógico investigativa, en esta parte del proceso didáctico se logra la formación consciente de la representación simbólica comprensiva-interpretativa de otros imaginarios donde confluye la música como eje de desarrollo, en consecuencia, se integraron a la didáctica y al currículum, performance, historias de vida, cuentos de tradición oral, ritmos folclóricos, análisis de versos, dramatizaciones, lecturas preliminares de cuentos animados, el arte del Carnaval de Barranquilla, la leyenda de Francisco El Hombre; El hombre caimán: La llorona loca, y otras tradiciones orales del hombre Caribe de Colombia. En síntesis, tanto ellas (ellos) los educandos y el orientador, incursionaron en una nueva estructura curricular, donde la música que ejercitaron los estudiantes, ellos las puedan ofrecer a las escuelas como espacio abierto, y mediación social integrador y forjador de capacidades meta-cognitivas y de bienestar comunitario. (Pérez, 2008, P. 66). 
Otro de los temas transversales de la propuesta tuvo que ver con temas ambientales, desde el cual la música fue abordada a partir del diseño de talleres para la construcción divergente del conocimiento del mundo ecológico, científico, cultural, económico, político, social y ético, filosófico, psicológico, etc. (Pérez, 2012, P.166).

En el estudio la evaluación cualitativa y de valoración por logros, fue tenida en cuenta en este nuevo enfoque educativo lo que señala (el artículo 51 del Decreto 1860,1994$)$, respecto al concepto pedagógico y práctica evaluativa conducente a la formación, la reflexión y el compromiso de responsabilidad social que representa la comunidad educativa. Lo anterior en consonancia con la Resolución No 2343 del 5 de junio de 1995, en lo relacionado con el establecimiento de logros e indicadores correspondientes a la educación formal. En tal sentido, el sistema de evaluación lo orientamos hacia una formación integral, que reglamenta el Estado como política educativa que encamina los procesos de enseñanza-aprendizaje hacia una educación de calidad que le posibilite a los (las) educandos desarrollar competencias comunicativas de carácter interpretativo, argumentativo, propositivo y todas aquellas dimensiones sociales, afectivas, psicológicas, actitudinales, volitivas, los valores, la atención, entre otras, logrando así impulsar el desarrollo de las capacidades cognoscitivas de los y las alumnos desde los diferentes niveles educativos.

No obstante, la evaluación cualitativa mediada por el lenguaje de la música fue asumida con una actitud formativa, donde el proceso de enseñanzaaprendizaje, estuvo encaminado a impactar positivamente la integración social, los afectos, la imaginación, la originalidad, y, en definitiva, la valoración significativa desde la individualización y la socialización del sujeto (Read, 1982: 27). El proceso didáctico constructivista se caracterizó por la implementación de una evaluación por procesos comprensiva e interpretativa de los educandos y de lo que para ellos significaban los lenguajes de la música tratados integralmente. De esa manera se dio cuenta de sus comportamientos en la producción intelectual de conocimientos que surgieron como necesidades en el contexto investigando, y, ellos (as), pudieron proponer formas de solución de situaciones problémicas. Según Romero. (1999) "en esta concepción, la evaluación no es un componente más de la práctica docente, sino que es asumida como la que hace posible la práctica pedagógica multidimensional". 
En consecuencia, el sistema de evaluación propuesto contempla las tres estrategias básicas de la misma: La autoevaluación, como el proceso en donde los sujetos evaluarán sus propias acciones, incluyendo a los estudiantes, a partir de criterios acordados previamente; la coevaluación: aquí los actores se evaluarán recíprocamente por grupos y actividades afines; y la heteroevaluación, esta les brinda la posibilidad de evaluar las acciones de desempeño de otro u otros (as) actores implicados en el proceso. (Pérez, 2012, p. 166).

Por otro lado, la experiencia como docente en investigación de didácticas específicas de la música, el sistema de evaluación propuesto buscó la cualificación e integración permanentemente de los educandos en contexto y demás escenarios en donde se ejerciten los diferentes eventos y actos pedagógicos que se realizan con esta disciplina. En tal sentido, articulamos a esta propuesta las bases teóricas de una evaluación que se fundamenta en jalonar procesos sistemáticos, secuenciales y dinámicos, teniendo en cuenta que:

A) La pedagogía como campo del conocimiento sus acciones están centrada en el alumno y en los procesos.

B) La investigación fue vista como fuente de solución de problemas y con carácter participativo.

C) La didáctica fue dinamizada como proceso de flexibilidad en la conducción mancomunada entre las situaciones individuales y colectivas del alumno y el medio.

D) El currículum en este sentido se visibiliza como espacios de integración de los sujetos, los lenguajes de la música y otras áreas del conocimiento.

Por último, la propuesta didáctica constructivista alternativa, apunto en todo momento a lograr el fortalecimiento de la participación de los actores del proceso educativo a través de estrategias y las acciones que condujeron a la toma de decisiones en un currículo donde la música es su eje transversal". (Asprilla, 2002, p. 16).

Se infiere en este entramado teórico curricular, que los supuestos epistemológicos, ontológicos, retóricos y metodológicos, emergente en el estudio, sirvieron para fundamentar el enfoque estructural de la propuesta, develándose así en esta construcción: la selección, organización, 
sistematización y apropiación del conocimiento musical, enfatizando sobre los propósitos del método sensorio-motor (estimulación de la experiencia sensorio-motora del ser musical), desde un marco histórico cultural del conocimiento que es transformado integralmente mediante la articulación de la sensorio-motricidad con la Zona de Desarrollo Próximo. Perspectiva teórica concebida para desarrollar múltiples competencias en la comunicación y construcción de discursos musicales en los cuales se articularon factores científicos, étnicos, locales, regionales, nacionales e internacionales, y donde la cultura del contexto (la tradición oral) se constituye en mediación fundamental de un conocimiento que se pone acorde con las exigencias de la pedagogía social en la contemporaneidad. (Pérez, 2006, P. 335).

\section{Conclusiones}

Hn consecuencia con todo lo explicitado en esta elaboración discursiva, se
concluye que: Las (los) estudiantes lograron transitar libremente por espacios de inclusión, interacción y relación intersubjetiva, con democracia participativa, desde una educación libertaria, progresiva y emancipadora de pensamiento iregresivo? Lo que en otros contextos formativos de la Universidad impedían el desarrollo integral de los estudiantes (Freire, 1974, p.339).

Se logró afianzar reflexivamente los vínculos socio-afectivos y cognitivos, en la comunidad educativa y el contexto. No obstante que en el proceso se indujeron las actividades para jalonar las dimensiones y capacidades a desarrollar con los jóvenes de diferentes énfasis de estudio en la universidad, diagnosticando e identificando aptitudes y actitudes indispensables para el fomento de una educación musical integradora.

El nuevo diseño curricular desde la perspectiva didáctica constructivista alternativa, fue fundamentada para que los practicantes la puedan desarrollar en otros niveles de formación y edades cronológicas más avanzados, con el fin de potencializar en las (os) educandos competencias múltiples a través de una educación musical destinada a formar para la vida, acorde con las exigencias de la globalización, la competitividad del conocimiento y el mundo de las competencias comunicativas, científicas, tecnológicas y sociales en la contemporaneidad.

El sistema de evaluación que sustenta la propuesta, intenta mostrar los elementos del currículo que influyen en los procesos de desarrollo humano y 
en los sistemas de enseñanza, evaluación y aprendizaje de la música, logrando en el contexto la calidad social, y la excelencia educativa, enmarcados en los lineamientos curriculares de la educación, y en las políticas institucionales del Estado que se establecen a través de la Constitución Política de Colombia (1991), la Ley General de la Educación (Ley 115, 1994), la Educación Superior (Ley 30, 1992), y todas aquellas disposiciones legales que emanan del Ministerio de Educación Nacional, organismos del Estado que dirigen el sistema educativo colombiano.

El estudio enfatiza en cómo pensar en una docencia que apunte a la formación de ciudadanos-educadores autónomos, críticos, democráticos; "que trabajen permanentemente por el reconocimiento y aceptación de los otros." (Serie Formación de maestros, 2002). Desarrollando así una actividad docente que articule transdisciplinariamente saberes pedagógicos y específicos de la música, al tiempo que los conocimientos previos de los educandos, en interacción con las teorías, los conceptos disciplinares de la música, tengan validez y presencia en el accionar cotidiano de los educadores.

La generación de una didáctica constructivista alternativa como disciplina activa, producto de la reflexión personal y colectiva de la comunidad educativa, como contribución a resolver y transformar problemas fundamentales, que le atañen a la formación de conocimiento científico y de desarrollo humano integral en el contexto" (Revista Facultad de Ciencias de la Educación, 1999).

La implementación de una nueva didáctica constructivista alternativa de la música y del currículo, en todo momento enfatiza en la canalización y ejercitación de dimensiones, capacidades y competencias, tal como lo exige la propuesta de educación artística del Ministerio de Educación Nacional, quien señala que:

La propuesta apuntó al desarrollo de dimensiones y competencias cognoscitivas, hacia la comprensión de cómo el área de Educación Artística asume que la razón de ser de todo el sistema educativo es el ser humano, independientemente de supuestos contractuales de su vida. Desde esta normatividad se formulan los siguientes interrogantes: ¿Cómo organizar la clase? ¿Cómo utilizar los recursos materiales existentes? ¿Cómo organizar los contenidos de los diferentes saberes? ¿Cómo hilvanar las actividades que corresponden a la vez a objetivos propios de la disciplina y a aquellos propios 
de la interdisciplinariedad? (Lineamientos curriculares de la educación artística, 2000).

Desde la nueva propuesta didáctica constructivista alternativa se devela que, es indispensable desarrollar el pensamiento contemplativo (Percepciones propias y de otros, evocaciones, cambios de actitud) así como el desarrollo del pensamiento simbólico: (Transformación de sensaciones, sentimientos, habilidades comunicativas, dominio técnico y tecnológico). Por otro lado, el desarrollo del pensamiento reflexivo se piensa dimensionar a través de la organización del conocimiento equilibrado...

"El desarrollo del pensamiento valorativo (comparación, apreciación, formación de juicio crítico, pertinencia del sentido estético y cultural). Desarrollo de competencias comunicativas (interpretativas, argumentativas y propositivas) y todas aquellas que estimulen el desarrollo de múltiples competencias en el ser humano al ejercitar sus estructuras cognoscitivas." (Lineamientos curriculares de la educación artística, 2000).

En síntesis, la importancia de la puesta en marcha de la propuesta curricular transversal desde donde se considera lo significativo que resulta que todo programa académico posibilite la creación de espacios de reflexión en los cuales desde la práctica pedagógica investigativa se recontextualice y resignifique el conocimiento producido por las comunidades local, regional, nacional y establecer la comunicación del contexto con los factores universales.

Repensar el gran valor formativo integrador que tiene la música como constructo de proyecto de vida, y como surgimiento de innovación pedagógica, didáctica que promueve la formación de procesos cognoscitivos, afectivos, actitudinales y saberes socioculturales como alternativas de cambio, la generación de nuevos saberes, la solución de problemas y necesidades, la transformación del contexto educativo y la comunicación permanente con el entorno social.

\section{REFERENCIAS BIBLIOGRÁFICAS}

ÁLVAREZ Rodríguez, José (2001): Tesis doctoral. Análisis de un modelo de educación integral. Universidad de Granada. Facultad de Ciencias de la Educación. Granada (España).

ASPRILLA Mosquera, Francisco Adelmo (2002: 16): Propuesta curricular educativa. Secretaría de Educación Distrital, Barranquilla. 
FERNÁNDEZ Batanero, José María (1992). La organización de los contenidos en el marco de la atención de la diversidad. (Consultado en Web, noviembre 6 de 2014). Universidad de Sevilla, España.

FREIRE, Paulo (1974). Educación y cambio. Ed. Búsqueda. Buenos Aires.

GARCÍA Canclini, Néstor (1995). Consumidores y ciudadanos. Conflictos multiculturales de la globalización. Editorial Grijalbo. México.

HABERMAS, Jürgen (1948). El discurso filosófico de la modernidad. Madrid, Taurus.

IBÁÑEZ, Jesús. (1985): Del algoritmo al sujeto: Perspectiva de la investigación social. Siglo XXI, Madrid.

IBÁÑEZ, Tomas. (1990): Aproximación a la psicología social. Sendai, Barcelona.

LEY GENERAL DE EDUCACIÓN (Ley 115-1994). Ministerio de Educación Nacional. Bogotá, D.C.

LOBO, Álvaro (1999): Propuesta curricular. Educación Artística y Cultural. Modalidad presencial. Universidad del Atlántico.

MAGENDZO, Abraham. (1986). Currículum educación para la democracia en la modernidad. Instituto para el Desarrollo de la Democracia Luis Carlos Galán Sarmiento. Santafé de Bogotá.

MARAVILlAS Díaz, (2004). La música en la educación primaria y en las escuelas de música: La necesaria coordinación. Revista Electrónica Complutense de Investigación Musical, Vol. 1 Núm. 2. Artículo en línea. Tomado de internet, Marzo 15. 2008). http://www.ucm.es/info/recien

MINISTERIO DE EDUCACIÓN NACIONAL. Ley General de Educación. (Ley 115 1984). Santafé de Bogotá, D.C.

-- Ley de Educación Superior (ley 30 de1992). Santafé de Bogotá, D.C.

- Didáctica de la Educación Artística (2000). Santafé de Bogotá, D.C.

Decreto (1860-1994). Santafé de Bogotá, D.C.

(2000): Lineamientos curriculares Educación Artística: 2000 2009. Bogotá, D.C.

(2002). Serie Formación de maestros: Articulación preescolar primaria. El desarrollo del niño y la niña de preescolar y primaria y el papel de las áreas obligatorias y fundamentales. M.E.N. Bogotá.

Resolución No 2343 del 5 de junio de (1995).

NúÑEZ, Violeta. (1990): Modelos de educación social en la época contemporánea. PPU, Barcelona.

PÉREZ HERRERA, Manuel Antonio (2003): Pedagogía musical en el contexto de la educación básica. Ediciones Son de Negro. Barranquilla. 
(2006): Integración de la música como eje transversal de las estructuras curriculares del programa académico de educación artística, Universidad del Atlántico. Tesis de Maestría. Universidad del Norte, Barranquilla.

(2008): La música como discurso dialógico e interdisciplinario en las instituciones de educación superior: una propuesta de integración curricular (trabajo inédito, en revisión para publicación). Universidad del Atlántico, Barranquilla.

(2008): Evolución de la práctica pedagógica como dispositivo escolar y discursivo en educación artística - musical. Revista Latinoamericana en Estudios Educativos, volumen 4. Maestría en Educación. Doctorado en Ciencias de la Educación, Rudecolombia, Universidad de Caldas, Manizales, Colombia.

(2008): Una pedagogía de salvaguardia del Carnaval de Barranquilla. (Capítulo de libro Pensar el Caribe II). Editorial Universidad del Atlántico.

(2010): La música como discurso dialógico e interdisciplinario en las instituciones de educación superior. Edición Universidad del Atlántico. Barranquilla.

(2011): El Carnaval de Barranquilla como fuente de pedagogía. Revista El Artista. Número 4, noviembre. Universidad de Pamplona.

(2012): Las estructuras del lenguaje musical. Edición Universidad del Atlántico.

Barranquilla.

(2012): Integración de la música como eje transversal de la estructura curricular de los programas académicos artístico musical de la Universidad del Atlántico. Tesis Doctoral. Rudecolombia - Universidad de Caldas, Manizales.

(2013): Integración una pedagogía de la educación social. Artículo. Revista Escenarios. Programa Posgrado Maestría. Universidad Autónoma del Caribe. Publicación Semestral -Volumen $N^{\circ}$ 11. Diciembre, 2013, Barranquilla.

(2015): La música como eje transversal del conocimiento. Electiva de Contexto. Universidad del Atlántico. Barranquilla.

PIAGET, Jean (1978). Una didáctica fundada en la psicología de Piaget. Por A.E.B.L.I. Hans. Kaperlesz. Buenos Aires.

(1954 - 1984): Psicología de la inteligencia. Buenos Aires. Siglo XX.

PROYECTO ACADÉMICO CURRICULAR (1999): Facultad de Ciencias de la Educación. Universidad del Atlántico. Barranquilla.

QUiNTANA, José María (1976): Pedagogía social y sociología de la educación, I. Análisis comparativos de ambos conceptos y sus analogías. Perspectivas Pedagógicas. Madrid, España.

READ, HERBERT (1982) Educación por el arte. Paidós. Educador, Barcelona. Buenos Aires. 
ROMERO, Hernando (1999): Proyecto curricular. Revista Facultad de Ciencias de la Educación Universidad del Atlántico, Barranquilla.

SACRISTÁN J. J (1980): La pedagogía por objetivos: Ediciones Morata. , Madrid- España.

(1992): El currículo una reflexión sobre la práctica. Madrid, Ediciones Morata. Madrid - España.

STENHOUSE L (1997). Investigación y desarrollo curricular. Ediciones Morata. Madrid.

VYGOTSKI, L. S. (1934/1991). Pensamiento y lenguaje. En L.S. Vygotsky obras escogidas Tomo II. Madrid: Visor/ MEC.

(1995). Historia del desarrollo de las funciones psíquicas superiores. En L.S. VYGOTSKI Obras escogidas Tomo III. Madrid: Visor. 